\title{
The many faces of SMN: deciphering the function critical to spinal muscular atrophy pathogenesis
}

\author{
Justin $G$ Boyer ${ }^{1,2 *}$, Mélissa Bowerman ${ }^{1,2 *}$ \& Rashmi Kothary ${ }^{11,2,3}$ \\ 'Ottawa Hospital Research Institute, Regenerative Medicine Program, ON, Canada \\ 2 Department of Cellular and Molecular Medicine, University of Ottawa, ON, Canada \\ ${ }^{3}$ Department of Medicine, University of Ottawa, ON, Canada \\ †Author for correspondence: Tel.: +1 6137378707 = Fax: +1 6137378803 = rkothary@ohri.ca \\ *These authors contributed equally to the work
}

Spinal muscular atrophy (SMA) is the leading genetic cause of infant death, affecting 1 in 6000-10,000 live births. SMA is an autosomal recessive disorder characterized by the degeneration of $\alpha$-motor neurons, and lower limb and proximal muscle weakness and wasting. SMA is the result of the deletion of or mutations in the survival motor neuron $(S M N) 1$ gene. Currently, our understanding of how loss of the widely expressed SMN leads to the selective pathogenesis observed in SMA is limited. Here, we discuss the known nuclear and cytoplasmic functions of the SMN protein and how they relate to the SMA pathology reported in motor neurons, striated muscle and at neuromuscular junctions. While a vast amount of work in various cell and animal models has increased our knowledge of the many functions of the SMN protein, we have yet to come to a full understanding of which role(s) are central to SMA pathogenesis.

Spinal muscular atrophy (SMA) is the most common genetic disease resulting in infant death, affecting approximately 1 in 6000-10,000 births $[1,2]$. This autosomal recessive disease is characterized by a loss of $\alpha$-motor neurons in the spinal cord and brain stem, accompanied by atrophy of the limbs and trunk musculature, which eventually lead to paralysis and in severe cases, death [1].

Spinal muscular atrophy is a heterogeneous disease and its clinical manifestations are classified based on age of onset and severity of symptoms (Table 1). Type 0 SMA has a prenatal onset and is typified by reduced fetal movements in utero and early neonatal death [3,4]. Types I, II and III all have an infant/childhood onset of disease; however, type I SMA (also known as Werdnig-Hoffman disease) is the most severe form and afflicts patients with symptoms before 6 months of age. These patients are never able to sit up and usually die before 2 years of age due to respiratory distress. Type II and III SMA (also known as Kugelberg-Welander disease) are milder forms where patients exhibit symptoms between 6 months and 17 years of age. Type II children are generally able to stand and sit but not walk, while type III adults have the ability to walk if aided $[5,6]$. Finally, individuals with type IV SMA, an adult-onset form of the disease, develop symptoms over the age of 30 years [2].
At the genetic level, SMA is the result of homozygous mutations or deletions of the survival motor neuron $(S M N) 1$ gene located on human chromosome 5q13 [7]. SMN has been highly conserved throughout evolution with almost all eukaryotic organisms studied to date having one single copy of the gene. In humans, however, there is a duplication of the $S M N$ gene resulting in two near-identical copies known as SMN1 and SMN2 [7,8]. The critical difference between $S M N 1$ and $S M N 2$ is a $\mathrm{C}$ to $\mathrm{T}$ substitution in the SMN2 gene at position 6 of exon 7 [9]. SMN1 expresses a full-length protein while $S M N 2$ predominantly expresses a truncated and unstable isoform of the protein, termed $\triangle 7 \mathrm{SMN}$, characterized by a deletion of exon 7 [7]. Recently, it was shown that the instability of the $\triangle 7 \mathrm{SMN}$ protein is due to a degradation signal (degron) created by the exclusion of exon 7 in the SMN2 transcript [10]. While deletions or mutations in SMN1 but not SMN2 cause SMA, the latter can modulate the severity of the disease through its copy number owing to its production of a small amount of full-length protein [7]. Indeed, patients affected by the milder forms of SMA generally have a higher copy number of the $S M N 2$ gene [11]. Thus, SMA is considered to be a dosage-sensitive disorder.

The full-length SMN protein $(38 \mathrm{kDa})$ is expressed in all cells of the developing embryo, albeit with a developmental and tissue-specific

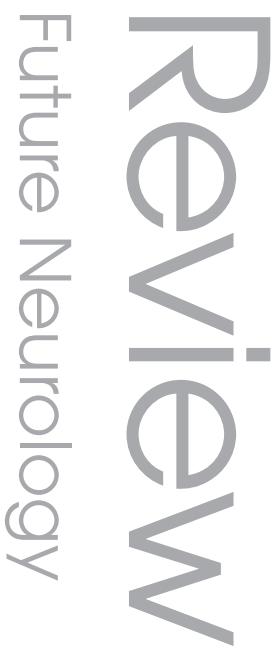

\section{Keywords}

actin dynamics

- neurodegeneration

- preclinical models a snRNP

assembly $=$ spinal muscular

atrophy = survival

motor neuron

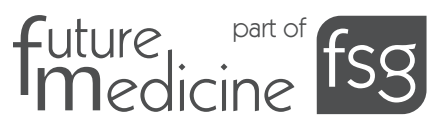




\begin{tabular}{|c|c|c|}
\hline SMA type & Age at onset & $\begin{array}{l}\text { Physical characteristics that } \\
\text { typify the disease }\end{array}$ \\
\hline Type 0 & Prenatal & Fetus displays reduced movement \\
\hline Type I (Werdnig-Hoffman disease) & $<6$ months & Affected children are never able to sit \\
\hline Type II & $<18$ months & $\begin{array}{l}\text { Affected children cannot stand or sit } \\
\text { without aid }\end{array}$ \\
\hline Type III (Kugelberg-Welander disease) & $>18$ months & $\begin{array}{l}\text { Affected children can walk } \\
\text { without help }\end{array}$ \\
\hline Type IV & Adulthood & $\begin{array}{l}\text { Mild weakness of the } \\
\text { proximal muscles }\end{array}$ \\
\hline
\end{tabular}

modulation in levels [12]. The protein is localized in the cytoplasm, in punctate nuclear structures known as Gemini of coiled bodies (Gems), as well as in axons and growth cones [13-16]. It remains unclear which of these different localizations of the SMN protein is relevant to SMA pathogenesis. Indeed the tissue-specific requirement for $S M N$ is also unclear, and although SMA is predominantly considered to be a motor neuron disease, the involvement of muscle in the pathophysiology has recently been highlighted [17-19]. Thus, whether SMA is due to the loss of a housekeeping or a cell-specific function of the SMN protein is a question that remains unanswered.

To better understand how deletions or mutations in SMN1 lead to SMA pathogenesis, various mouse models have been developed [20]. Interestingly, the complete absence of the SMN protein in mice $\left(\mathrm{Smn}^{-/}\right)$proved to be lethal to embryos, emphasizing the necessity of the $S m n$ gene for survival [21,22]. In an innovative approach, the human SMN2 gene was used to rescue the embryonic lethality in $S m n^{-1-}$ mice $[22,23]$. This approach was useful in demonstrating that a high copy number of SMN2 leads to a milder phenotype, while mice having only two copies of the SMN2 gene display a severe phenotype reminiscent of type I SMA [23,24]. Importantly, the subsequent cross of the severe SMA mouse model $\left(S m n^{-1} ; S M N 2\right)$ with transgenic mice expressing the $S M N \Delta 7$ protein has generated a SMA mouse model that survives longer ( $\sim 14$ days instead of 6 days) and thus, is the most commonly used for molecular, morphological and therapeutic studies [25]. Recently, our laboratory has generated an intermediate SMA mouse model $\left(S m n^{2 B /}\right)$ that does not contain a SMN2 transgene but instead harbors a substitution of three nucleotides within the exon splicing enhancer of exon 7 of the mouse $S m n$ gene [26]. The $S m n^{2 B /-}$ mouse model displays a milder SMA phenotype than the $S m n^{-1-}$;SMN2 model due to slightly higher SMN protein levels. All models have been extremely useful in making progress towards identifying pathways important for SMA pathogenesis.

However, despite numerous studies investigating the various functions of the SMN protein, a direct explanation for the specific motor neuron degeneration in SMA is presently lacking. In this article, we will present an overview of the known interactions and functions of SMN and the relevance to SMA pathogenesis. We will also highlight how these findings are bringing us closer to a better understanding of how loss of a multifunctional and omnipresent protein results in the selective loss of a specific cell type.

\section{SMN function in the nucleus Small nuclear ribonucleoprotein assembly}

The full-length SMN protein is expressed in all cells studied to date, localizing in both the cytoplasm and in nuclear Gems [13,14]. While Gems physically and functionally resemble Cajal bodies, they do not contain the protein coilin, a specific marker of Cajal bodies [27]. The SMN protein is part of a multiprotein nuclear complex that is comprised of SMN, Gemin2-8, upstream of N-ras (UNR)-interacting protein (Unrip) and Sm proteins, which together are essential for small nuclear ribonucleoprotein (snRNP) biogenesis [28-30]. In turn, snRNPs are the building blocks for the spliceosome. Following transcription, the pre-mRNA of protein-encoding genes is spliced to remove the introns, an RNA-processing step mediated by the spliceosome [31]. The collective data to date suggest that the SMN complex is crucial for snRNP assembly. Whether the disruption of this complex and reduced snRNP assembly is responsible for SMA pathogenesis remains the focus of ongoing studies. Over recent years, progress has been made regarding the sequential 
steps involved in pre-mRNA splicing, specifically snRNP assembly. Here, we describe our current understanding of this process in a step by step fashion.

During the initial steps of snRNP assembly, chloride conductance regulatory protein (pICLn) binds $\mathrm{Sm}$ proteins, thus acting as a chaperone to prevent unwanted association of RNA to Sm proteins or self $\mathrm{Sm}$ protein binding [32]. In addition, pICLn also associates and influences the activity of protein arginine methyltransferase (PRMT) 5 , which together with methylosome protein (MEP)50 forms a methyltransferase complex termed the methylosome [33-36]. PRMT5 is a type II methyltransferase that specifically methylates multiple arginine-glycine $(R G)$ residues of Sm proteins $[35,37,38]$. It is well established that the SMN Tudor domain is vital for Sm protein binding [39]. The direct interaction between the SMN Tudor domain and Sm proteins is mediated through the PRMT-induced symmetrical dimethylated arginines of $S \mathrm{~m}$ proteins, a critical step for snRNP assembly [38,40]. Furthermore, $\mathrm{Sm}$ protein methylation regulates the nuclear localization of snRNPs [40]. The key function of the SMN complex in snRNP assembly is to serve as a catalyst in arranging the $\mathrm{Sm}$ proteins in a heptameric open-ring configuration and assist in the association of the Sm core to the $\mathrm{Sm}$ site of uridine-rich snRNAs, thus forming a spliceosomal complex [32,41-43]. Indeed, Palfi et al. demonstrated in a SMN-depleted one-cell protozoan model (trypanosome), that SMN is important in assuring the accurate binding of $\mathrm{Sm}$ proteins to the Sm-binding sites of specific snRNAs [44]. In this process, the methylosome bound to the $S m$ proteins also associates with the SMN complex [45-47]. The pICLn chaperone dissociates from the methylosome, while PRMT5 and MEP50 appear to associate with the SMN complex given that both proteins were recovered in recent SMN interaction screens $[32,48,49]$. In the final step of cytoplasmic snRNP assembly, hypermethylation of the snRNA by the trimethylguanosine synthetase 1 (TGS1) occurs, thus producing a 2,2,7-trimethylguanosine (TMG) cap [50]. A role for SMN has previously been proposed as a recruiter and docking station for TGS1 [51]. The hypermethylation by TGS1 allows the SMN complex and associated snRNPs to interact with importin- $\beta$ and snurportin, and to be imported into the nucleus [52-55]. Once in the nucleus, snRNPs and the SMN complex localize to Cajal bodies through their interaction with coilin [56-58]. The recruitment of SMN to Cajal bodies appears to be methyl-dependent possibly through the methylation of the coilin C-terminal RG motif [47,57]. At present, the function of the SMN complex upon nuclear entry is not well defined and warrants investigation to further our understanding of pre-mRNA splicing. SMN depletion could thus affect any and/or all of the aforeementioned interactions necessary for precise snRNP biogenesis.

Although protozoa, yeast and even models such as Drosophila, can be advantageous in studying biological processes such as snRNP assembly [44,59,60], results obtained with such model organisms should be interpreted with caution in regards to SMA pathogenesis. In these models, snRNP assembly may function by different mechanisms owing to ortholog divergence of proteins, which can be quite significant in certain models [44]. This caveat needs to be accounted for when comparing snRNP assembly across different organisms.

Based on the involvement of SMN in mRNA maturation via its role in snRNP assembly, many research groups have focused on identifying the relevance and importance of snRNP assembly in SMA pathogenesis. Aberrant snRNP biosynthesis has been reported in cells from SMA patients as well as in vertebrate models of SMA [61-64]. Recently, a correlation has been demonstrated between general snRNP assembly activity in the spinal cord of SMA mice and disease severity [62]. Further analyses revealed that snRNPs comprised of the Sm class of snRNAs are preferentially reduced in the spinal cord of a severe mouse model of SMA ( $\mathrm{Smn}^{-1}$;SMN2) [62]. However, only one study, performed in a SMA zebrafish model, has reported a correlation between defects in snRNP assembly and motor axon degeneration [61]. In this study, injection of purified snRNPs prevented the axon outgrowth and pathfinding defects observed in SMN-depleted zebrafish. However, a contrasting study has subsequently demonstrated that various SMN protein mutants associated with motor axon pathology in zebrafish had no effect on snRNP assembly [65]. Thus, these contrasting results do not fully establish whether or not reduced snRNP biogenesis is directly responsible for the motor axon defects and degeneration in SMA.

\section{Pre-mRNA splicing}

Pre-mRNA splicing involves the excision of introns, and in the context of SMA, defects in this molecular process were first reported over a decade ago when a mutated form of SMN produced robust splicing inhibition in pre-mRNA in vitro assays [66]. More recently, splicing defects 
have been at the forefront of various studies to determine if defects in RNA metabolism are responsible for SMA pathology. Zhang and colleagues have observed that SMN reduction produces cell-type-specific changes in snRNA expression and profiles [67]. To address the possible consequence of this aberrant snRNP assembly, the authors studied pre-mRNA splicing patterns in the brain, spinal cord and kidney of SMA mice. They demonstrated that, at the peak of disease progression, large-scale tissue-specific defects in intron-exon splicing are apparent when SMN levels are reduced to pathogenic levels [67]. In another study, fibroblasts from SMA patients revealed an increased error rate in pre-mRNA splice-site pairing in comparison with controls [68]. These results suggest that in SMA, the pre-mRNA splicing accuracy is compromised and that the pathology of the disease is caused by widespread aberrant splicing. However, as these analyses were only performed in the later stages of disease progression, and none of the aberrantly spliced genes were linked to SMA pathology, the relevance of these findings still requires further investigation.

In another study, Bäumer and colleagues performed exon-array analyses to assess whether splicing defects preceded the onset of the SMA phenotype. In agreement with other studies, the authors conclude that the splicing changes observed in SMA mice ( $\mathrm{Smn}^{-1}$; $S M N 2 ; S M N \Delta 7$ and $S m n^{-1} ; S M N 2$ mice) are a late feature of the disease and thus may be secondary to the SMA pathology $[12,69]$.

The aforementioned studies on pre-mRNA splicing employed exon-arrays to assess splicing defects. A caveat of this method is that it cannot detect intron-specific splicing defects [60]. This has prompted others to study splicing in SMA using a different approach to overcome this limitation. Using fission yeast cells expressing a temperature-sensitive degron of the $S M N$ gene, Campion et al. observed perturbed snRNP assembly and altered intron splicing at the degron-inducing temperature [60]. Of note, the authors also observed snRNP assembly defects at a temperature lower than that required to activate the temperature degron, suggesting that the fusion protein itself had deleterious effects [60]. Furthermore, it remains to be seen if the changes in intron splicing occur prephenotype and if these splicing alterations are part of the primary mechanism affected in SMA pathogenesis.

With regards to snRNP assembly and RNA splicing, several questions remain to be answered to convincingly link the housekeeping functions of SMN to SMA pathogenesis. Perhaps the most important realization is that no causal link has yet been established between the identified aberrantly spliced mRNA targets and the specificity of SMA pathogenesis. Indeed, considering that proper transcript processing is necessary and that SMN levels are reduced in all cell types of SMA mouse models and patients studied, the question of motor neuron-specific death in SMA remains unresolved. It is thus possible that the observed aberrant splicing is in fact due to secondary and/or cellular stress effects resulting from the cellular loss of the SMN protein. Collectively, these concerns have pushed forward the search for roles of SMN in motor neuron processes where its function is much less understood, leaving open the possibility that the role of SMN in snRNP assembly is not the primary pathogenic origin of SMA.

\section{SMN function \& SMA pathology in motor neurons}

In addition to the role of SMN in snRNP biogenesis, interactions with numerous cytoplasmic proteins unrelated to snRNPs or splicing, suggests that SMN has additional functions. Furthermore, defects in the general housekeeping role of SMN in the regulation of RNA metabolism do not explain how deletions or mutations in SMN1 specifically affect the $\alpha$-motor neurons in SMA patients. Thus, various groups have focused their efforts on assessing the effects of SMN depletion in neuronal models and how this might result in SMA pathogenesis. Collectively, these studies suggest a role for SMN in neurite outgrowth, neuronal differentiation and axonal pathfinding, as well as in the regulation of actin dynamics [70-73].

A first step to identifying a neuronal-specific role for SMN was determining if and when it was expressed in neurons. Interestingly, SMN expression increases in both murine neurosphere-derived neural stem cells and PC12 cells during neuronal differentiation [72,74]. Fan and Simard reported that SMN localizes in growth cones of mouse embryonal teratocarcinoma P19 cells during neuronal differentiation [70]. In cultured mouse neurons, $\mathrm{SMN}$ is found in granules within neurites and at growth cones $[70,75]$. The expression and distribution profiles of SMN in these cells therefore suggest a role for SMN in neurons.

The distribution of SMN in motor neuron processes appears to be regulated by a sequence in exon 7 of the gene and deletion of this sequence 
leads to the absence of SMN outside the nucleus and was consequently coupled with a decrease in neurite outgrowth $[74,75]$. Additional work performed in PC12 cells and in primary cultures of mouse motor neurons supports a role for SMN in neuronal outgrowth [76]. Similarly, knockdown of the SMN protein in zebrafish resulted in aberrant motor axon outgrowth and pathfinding [71]. In the same study, assessment of different neuronal populations revealed that knockdown of SMN was restricted to motor neurons, suggesting cell-autonomous defects. These findings in various cell culture and animal models thus suggest a neuronal-specific role for SMN in motor neuron outgrowth. Surprisingly, morphological analyses of severe SMA mice at various presymptomatic stages show normal axonal formation and outgrowth [77,78]. Thus, it remains unclear whether SMA pathology is due to defects in the outgrowth of the motor neurons or simply to their subsequent degeneration. Identifying how SMN modulates axonal outgrowth and the biochemical pathways involved would therefore provide us with a better understanding of SMN's neuronal-specific function.

\section{SMN function in motor neuron actin dynamics}

The actin cytoskeleton and its dynamics play a crucial role in neuritogenesis as well as in neurite elongation and branching [79-81]. Actin is the most abundant presynaptic protein, playing roles in synaptic vesicle organization, mobilization and trafficking [82-86]. Considering the phenotypic defects observed in SMN-depleted neuronal cells, a role for SMN in the regulation of actin dynamics, whether direct or indirect, has been investigated.

\section{$\beta$-actin mRNA axonal transport}

An additional role explored for SMN in motor neurons is in axonal transport. Indeed, SMN has been localized within actively transported granules in neurites of cultured motor neurons, where it associates specifically with Gemin proteins but not the $\mathrm{Sm}$ proteins [29,87-89]. This suggests that the role of these transport ribonucleoprotein granules is independent of snRNP assembly. In fact, they could be responsible for the shuttling of components from the cell body to the growth cone to ensure proper neuronal development.

In neurons, subcellular mRNA trafficking and localization are important in modulating local protein translation. This process is critical for the generation of neuronal cell polarity and for the proper functioning of a neuron. It is thus of interest to note that the transport of $\beta$-actin mRNA to axons and growth cones is perturbed in primary motor neurons isolated from the $\mathrm{Smn}^{-1} ; S M N 2$ mouse [76]. In this respect, $\mathrm{SMN}$ has been shown to interact with the RNA-binding heterogeneous nuclear ribonucleoprotein R (hnRNP-R), previously described as functioning in mRNA transport to the nerve terminus [76,90-92]. Indeed, the SMN-hnRNP-R interaction is necessary for hnRNP-R to bind to $\beta$-actin mRNA [76]. This interaction is required for correct $\beta$-actin mRNA translocation along the axon to the growth cone and thus essential for neuronal outgrowth and presynaptic differentiation [76,91]. Recently, the analysis of the SHSY5Y neuroblastoma cell line showed the colocalization of $\beta$-actin and cytoplasmic SMNcontaining granules [89], thus supporting a role for SMN in $\beta$-actin mRNA transport. In fact, SMN-depleted motor neurons display reduced localization of both hnRNP and $\beta$-actin along the axons and at the growth cones [76]. A role for $S M N$ in the localization of $\beta$-actin is further supported by its interaction with another $\beta$-actin binding partner, $\mathrm{K}$ homology-type splicing regulatory protein (KSRP) [93]. Interestingly, defects in actin organization have also been observed in SMN-depleted PC12 cells. While one study demonstrated an accumulation of F-actin at the cell periphery [94], another showed a change in G-/F-actin ratio due to an increase in the F-actin component [74]. Whether the above-described defects in actin organization are directly or indirectly due to the regulation of actin mRNA still needs to be established. Nevertheless, together, these findings suggest that $S M N$ plays an important functional role in the regulation of actin mRNA localization.

The disruption in $\beta$-actin mRNA and protein localization could therefore be an important initiating event in the eventual degeneration of the neuron. The large $\alpha$-motor neurons could be more sensitive to SMN depletion as it has been hypothesized that the weight and importance of the various functions of the actin cytoskeleton may depend on the properties of a particular neuronal cell and its synapse [79,85,95]. Recently, it was shown that motor neurons of SMA mice depleted of phosphatase and tensin homolog showed an increase in axon growth and survival, which were interestingly accompanied by a restoration of $\beta$-actin levels in their growth cones [96]. Strategies to restore $\beta$-actin in distal axons and growth cones of motor neurons might thus represent a viable therapeutic option for SMA. 


\section{SMN \& Profilin Ila in motor neurons}

In light of the observed defects in actin localization and organization in SMN-depleted neuronal cells, research groups have explored the impact of SMN depletion on the expression and regulation of proteins involved in the modulation of actin dynamics. One of these proteins is profilin IIa, a small actin-binding protein and regulator of actin dynamics. Profilin IIa is a neuronal-specific splice variant of the profilin II gene [97,98]. Through its polyproline motif, SMN interacts with profilin IIa in the cytoplasm, neurite-like extensions and in growth cones of PC12 cells [99,100]. In vitro experiments show that SMN can modulate actin dynamics by binding to profilin IIa and inhibiting its negative regulation of neurite sprouting and elongation $[100,101]$. Interestingly, SMN-depleted PC12 cells show defects in neuronal outgrowth and an increase in profilin IIa mRNA and protein [94]. Moreover, a reduction of differentiation of PC12 cells was reported upon SMN depletion suggesting that SMN may play a role in neuritogenesis. These defects were rescued when SMN-depleted PC12 cells were transfected with a SMN construct specifically containing the profilin-binding domain [74]. Immunofluorescence analysis of the spinal cord of the $S m n^{2 B /-}$ mice also shows an increase in profilin IIa staining intensity [26]. However, the genetic reduction of profilin II levels did not rescue the lifespan or SMA phenotype of these mice [26]. This particular finding does not negate the functional importance of the SMN-profilin IIa interaction on the modulation of actin dynamics and/or SMA pathology. This is particularly true when considering that the depletion of profilin IIa in a SMA mouse model may entirely abolish the formation of the SMN-profilin IIa complex and subsequently interfere with its normal function. Nevertheless, there is also the possibility that other actin regulators may be affected upon the reduction of the SMN protein and that their misregulation has a greater influence on SMA pathogenesis.

\section{Plastin 3 as a SMA modifier}

Another recently identified actin regulator and potential modifier of SMA pathology is plastin 3 [102]. Plastin 3 (also known as T-plastin or T-fimbrin) is involved in bundling, turnover and assembly of actin [103,104]. Analysis of SMA-discordant families identified plastin 3 as a positive modifier of SMA pathology, with asymptomatic females carrying the exact SMN1 mutations as affected siblings displaying a significant increase in plastin $3 \mathrm{mRNA}$ and protein levels [102]. The authors also show that SMN, plastin 3 and actin form a complex in mouse spinal cord and overexpression of plastin 3 in SMN-depleted PC12 cells and SMA mouse motor neurons lead to significant rescue of the defects in neurite length [102]. Interestingly, spinal cord and brain tissue from the $S m n^{2 B /-}$ mice have reduced levels of plastin 3 protein, although an increase in plastin 3 levels following a genetic manipulation of this SMA mouse model did not improve its lifespan or pathology [26]. This latter observation does not necessarily exclude plastin 3 as a positive modifier of SMA pathology. It is possible that the upregulation of plastin 3 in the $S m n^{2 B /-}$ mice did not occur at the appropriate developmental time point or at the correct biological and thus, functional level to result in any beneficial effect. Alternatively, it is possible that, as with profilin IIa, the misregulation of plastin 3 reflects a defect in upstream modulators of actin cytoskeletal dynamics.

\section{Rho GTPases in SMA pathogenesis}

Members of the Rho GTPase family function as major upstream regulators of actin dynamics [105]. The most studied and understood members of this family are RhoA, Cdc42 and Rac1. These small GTPases cycle between active (GTP-bound) and inactive (GDP-bound) states. Recently, it was shown that SMN-depleted PC12 cells displayed an increase in RhoA-GTP as well as a decrease in Cdc42-GTP [94]. This is of importance owing to the concurrent requirement of Cdc42 activation and RhoA inactivation for proper neuronal outgrowth and differentiation [106]. An increase in RhoA-GTP levels have also been observed in the spinal cords of $S m n^{2 B /-}$ mice at prephenotype and phenotype stages [107]. Furthermore, administration of the Y-27632 synthetic compound, an inhibitor of Rho-kinase (ROCK), which is a direct downstream effector of RhoA-GTP increased lifespan in the $S m n^{2 B /-}$ mouse model of SMA and improved neuromuscular junction (NMJ) maturity and muscle fiber size [107-109]. This work suggests that the manipulation of actin cytoskeletal dynamics could be a valuable therapeutic approach for the treatment of SMA.

The findings described above strongly support the hypothesis that misregulation of actin and its regulators are central to SMA pathogenesis. However, several key experiments are essential for a better understanding of how misregulation of actin cytoskeletal dynamics leads to the specific degeneration and loss of motor neurons observed in SMA patients. Indeed, it would be 
valuable to determine if restoring the proper localization of $\beta$-actin in axons and growth cones of SMN-depleted motor neurons rescues the neuronal outgrowth and differentiation defects. Furthermore, increasing plastin 3 levels in SMA mouse models would help determine the protective mechanism of this actin-bundling protein. Finally, although the rescue with Y-27632 is promising, this synthetic compound, as well as its US FDA-approved equivalent fasudil, should be tested in more SMA mouse models varying in disease severity. Whatever the outcome, these proposed experiments could provide us with a better clarity on the bearing of actin dynamics in SMA pathogenesis.

Based on the work described above, we propose a model where the central event upon SMN depletion is an abnormal localization and organization of actin (Figure 1). This in turn leads to abnormal regulation of various upstream and downstream modulators of actin dynamics, which in turn could lead to defects in axonal outgrowth and guidance as well as in NMJ maturity and activity. Clearly, a lot has to be done to test the veracity of this model.

\section{SMN function in neurodevelopment}

Owing to the early onset of SMA in its most severe form, it has been suggested that there is a neurodevelopmental component to the pathogenesis. A number of groups have therefore undertaken studies to investigate the developmental functions of SMN and the developmental consequences of a reduction in SMN. In mouse spinal cord, SMN expression is elevated during embryonic development and decreases after birth. Gabanella et al. have additionally shown that the activity of SMN in snRNP assembly is highest during embryonic and early postnatal development of the mouse CNS, followed by a sudden decrease [15,21]. Recently, a more in-depth analysis of SMN expression during murine embryogenesis demonstrated that at the earliest observed time point of embryonic (E) day 7, SMN expression is at its highest in the developing nervous system compared with other tissues [110]. In the human CNS, the SMN protein is similarly expressed at high levels during embryonic development and becomes apparent in motor axons at this time [111]. SMN protein may therefore be required during embryogenesis for normal CNS development, and SMN depletion would result in neurodevelopmental defects, which ultimately could contribute to aspects of SMA pathogenesis.

The impact of SMN depletion on neurodevelopment has been investigated in both zebrafish and mouse models. Depletion of SMN in zebrafish via antisense morpholinos resulted in an increase in motor axon truncations and aberrant branching [71]. Interestingly, analysis of E10.5 Smn ${ }^{-1}$;SMN2 mouse embryos revealed similar neurodevelopmental defects, such as altered cranial nerve morphology and truncation of the lumbar spinal nerves [12]. However, an earlier study in $\mathrm{Smn}^{-1-}$;SMN2 mice from

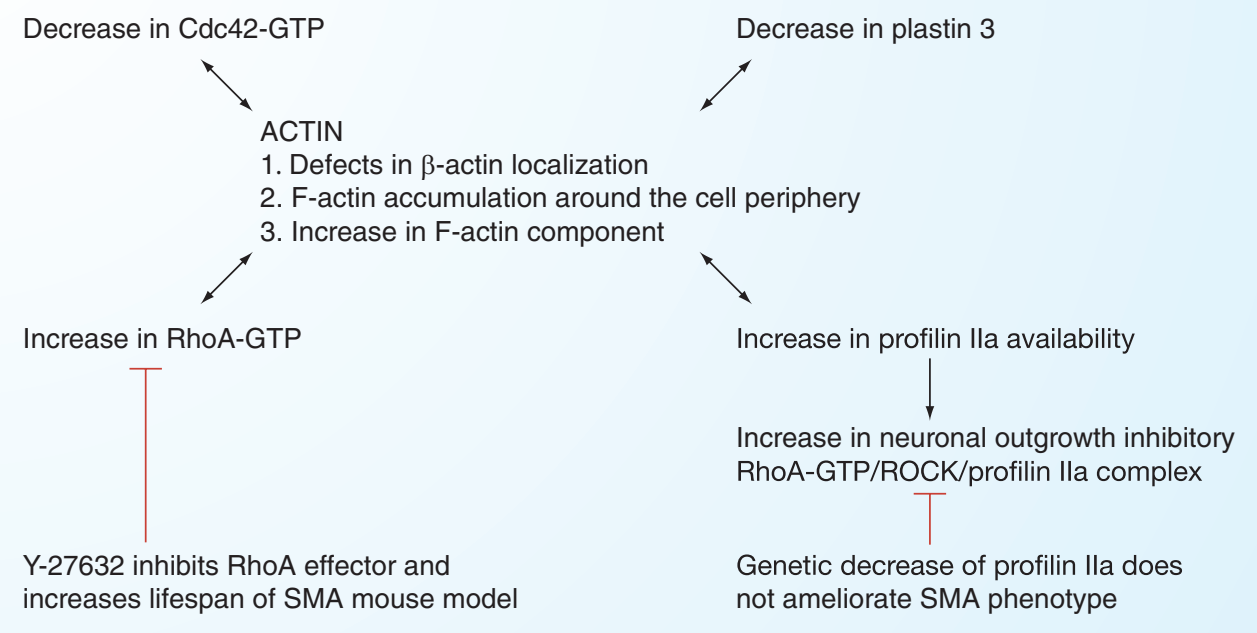

Figure 1. A proposed model of how survival motor neuron depletion impacts the regulation of actin cytoskeletal dynamics. The central event is the abnormal expression and localization of $\beta$-actin and F-actin. This in turn leads to defects in the expression and activity of major upstream and downstream regulators of actin dynamics, such as profilin Ila, plastin 3, RhoA-GTP and Cdc42-GTP. To date, only the modulation of the RhoA pathway, through a synthetic compound that inhibits its direct downstream target, has shown beneficial effects on survival in a spinal muscular atrophy mouse model. 
E10.5 to postnatal day 2 did not report any defects in axonal outgrowth, formation and branching [77]. Furthermore, Murray and colleagues demonstrated that axonal branching in SMA mice was indistinguishable from control littermates [78,112]. The discrepancies between studies may be due to differences in the genetic background of the mice used, which has been observed to have a significant affect upon lifespan and disease severity [12,24]. It would thus be interesting to determine if neurodevelopmental defects are dependent on disease severity by looking at milder SMA mouse models such as $\mathrm{Smn}^{+-} ; S m n^{2 B /-}$ and $S m n^{-1-} ; S M N 2(\mathrm{~N} 11 / \mathrm{N} 46$, with 3 SMN2 copies) [26,113,114].

\section{SMN function \& SMA pathology in striated muscle \\ Skeletal muscle}

While SMA is traditionally considered to be a motor neuron disease, a possible involvement of skeletal muscle in pathogenesis has been investigated $[17,18,115]$. Skeletal muscle defects, such as vacuolization and compromised sarcomere structures were reported in human SMA muscle cells co-cultured with rat spinal cord explants [115]. However these defects have not been observed in vivo $[115,116]$.

More current research has focused on determining if the SMN protein has a specific and independent role in muscle. In a study by Shafey et al., C2C12 myoblasts with reduced SMN expression displayed defects such as abnormal proliferation, aberrant myoblast fusion and malformed myotubes [18]. These findings demonstrate that reduced SMN levels can result in intrinsic muscle defects. Furthermore, a recent study on patient samples confirmed that SMA muscle displays smaller and disorganized myotubes as well as a delay in muscle growth and maturation [116]. The muscle-specific depletion of SMN in various conditional knockout mouse models also suggests a role for SMN in skeletal muscle. These mice show a severe dystrophic phenotype, myocytes with compromised sarcolemma, a decrease in muscle force as well as a reduced lifespan [17,117]. However, the limitations of the aforementioned mouse and cell-culture models are that they are not necessarily representative of the true SMA pathology. Indeed, the $\mathrm{C} 2 \mathrm{C} 12$ cell model lacks a motor neuron signal while the muscle-specific SMN-depleted mice do not have the residual full-length SMN and $\triangle 7$ SMN protein normally present in SMA patients. The relevance of these models have also been put into question owing to the fact that a liver-specific depletion of SMN protein resulted in mice with liver defects not normally present in SMA [18]. This implies that complete absence of SMN in any tissue may lead to severe defects and thus, does not convincingly argue for a role for the SMN protein in skeletal muscle in the context of SMA pathogenesis.

In Drosophila, SMN was shown to be a sarcomeric protein [119]. Moreover, it was found to interact with $\alpha$-actinin, a crosslinking protein that stabilizes actin microfilaments [119]. Follow-up experiments in mice confirm these findings and specifically identify SMN as a Z-disc component in skeletal and cardiac muscle $[19,48]$. Other proteins, such as Gemins and Unrip, are also present at Z-discs, likely forming a muscle-specific SMN complex [19]. However, the absence of snRNPs in purified myofibrils suggests that $S M N$ might have a function other than snRNP biogenesis at the Z-disc [19]. SMN staining was never fully assessed in the context of an intact muscle fiber. Therefore, the possibility that SMN plays a role in snRNP assembly in other muscle fiber compartments cannot be excluded. When compared with wild-type muscle, SMA myofibrils showed morphological defects such as vacuoles and abnormal Z-disc spacing. Although such structural defects were observed, it is unlikely that SMN plays a role in maintaining sarcomeric integrity given that the domain organization of the SMN protein does not support such an idea. Moreover, we have not observed any sarcomeric defects in the $S m n^{2 B /}$ mouse model at postnatal day 21 (Figure 2). It therefore remains unclear if SMN has a functional role at the sarcomere and if it has any impact on SMA pathology.

Studies have also shown that calpain proteases can remove the SMN protein from the Z-discs [19]. However the physiological relevance of this process is not fully understood. In addition, the function of the calpain-cleaved SMN product in muscle is unclear. Of potential interest, calpain levels increase in response to lack of neuromuscular activity [120]. Furthermore, a role for calpains has been established in muscle wasting, where they are responsible for the initial sarcomeric breakdown before the final proteosome-mediated degradation [121]. The direct consequence of SMN depletion on the SMN-calpain relationship and its relevance in SMA pathogenesis is still unknown. Thus, identifying the specific calpain responsible for the cleavage of SMN and understanding the significance of this process in health and disease may help decipher SMN's function in muscle and further our knowledge of SMA pathogenesis. 
To begin addressing the possible function(s) of SMN in skeletal muscle, our laboratory has performed a protein interaction screen and identified SMN-interacting proteins during varying stages of development in $\mathrm{C} 2 \mathrm{C} 12$ cells. Our findings suggest that the nature of the SMN-interacting protein varies during growth, early differentiation and late differentiation [48]. Indeed, the levels of snRNP assembly activity significantly decrease during $\mathrm{C} 2 \mathrm{C} 12$ myoblast differentiation, suggesting unique functions for SMN during growth and differentiation of muscle cells [110]. For this reason, we postulate that the function of SMN in muscle is dynamic and may differ from snRNP assembly during myocyte maturation.

To date, the most characterized muscle defect in SMA is muscular atrophy, which is likely attributable to the motor neuron degeneration. Muscle-targeting strategies to reverse atrophy have proven beneficial in several motor neuron diseases [122-124]. However, studies designed to stimulate muscle hypertrophy in SMA mice have generated mixed results $[125,126]$. A major difference between studies is in the methods used to target the same pathway. Clearly, more work is needed to determine if the targeting of muscle atrophy is a valid therapeutic approach for SMA.

The aforementioned studies have thus begun to shed light on the function of SMN in muscle. In a Drosophila model of SMA, the importance of SMN expression in both neurons and muscle has clearly been established. While reduction of SMN in either neurons or muscle proved to be lethal, its reduction in muscle accelerated lethality $[127,128]$.

To further assess the impact of SMN expression in muscle or neurons on SMA disease pathogenesis, a transgene encoding SMN was introduced in a severe mouse model $\left(\mathrm{Smn}^{-1}\right.$;SMN2) under the control of a muscle or a neuron-specific promoter [129]. A high expression of SMN in muscle was achieved using the human skeletal-actin promoter. This strategy produced a modest increase in survival in the $\mathrm{Smn}^{-1}$;SMN2 mice. Conversely, expression of SMN in neurons using the prion protein promoter had a greater impact on survival, but only when expressed at high levels. However, considerable leaky SMN expression was observed in spinal cord and skeletal muscle using the HSA and prion protein promoters, respectively. Therefore, it remains unclear what impact the specific overexpression of SMN in muscle has on the pathology of SMA mice. It is possible that the HSA promoter expresses SMN too late in myocyte differentiation to produce maximal
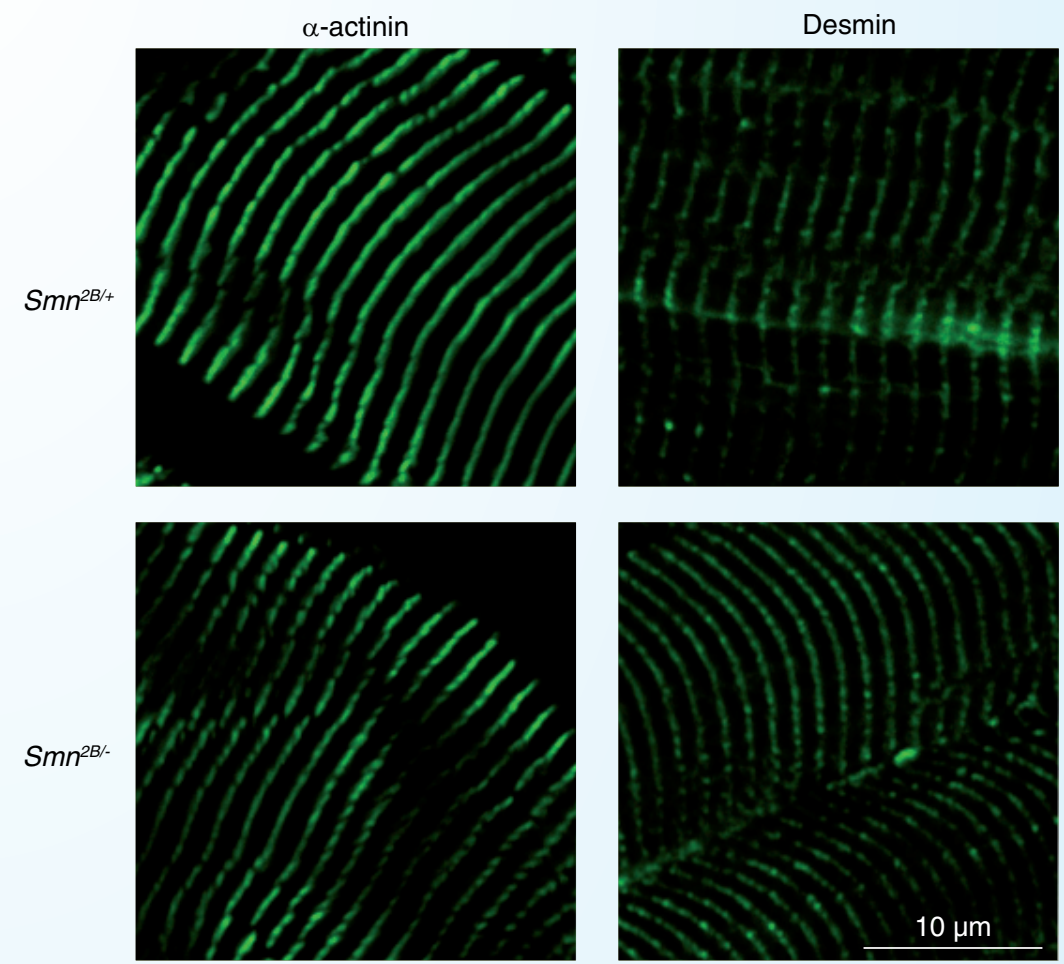

Figure 2. Muscle structure in spinal muscular atrophy mice. Sarcomere spacing and alignment are normal in spinal muscular atrophy (SMA) mice.

Longitudinal tibialis anterior muscle sections from control $\left(S m n^{2 B /+}\right)$ and end-stage SMA $\left(S m n^{2 B /-}\right)$ mice, were stained for desmin and $\alpha$-actinin, both known Z-disc markers. $n=3$ for both groups. Images were acquired using a Zeiss confocal microscope (LSM 510 META DuoScan).

Smn: Survival motor neuron.

benefits. The use of promoters from the myogenic regulatory factors, such as MyoD or Myf5, which are expressed at earlier stages of myocyte differentiation, may therefore yield more significant improvements in the survival of SMA mice.

\section{Cardiac muscle}

Similar to skeletal muscle, the heart displays a striated appearance owing to its sarcomeric organization. Interestingly, in mice, the SMN protein interacts with $\alpha$-actinin and localizes at the Z-discs in cardiac myofibrils [19]. There may thus also be a specific function for the SMN protein in cardiac muscle. Clinical reports on SMA patients do indeed support this hypothesis. The probability of an individual developing type 1 SMA (with only one SMN2 copy) and cardiac defects by chance is estimated at 1 in 50 million based on disease incidence alone [130]. A clinical study by Rudnik-Schoneborn et al. shows that three out of four SMA type 1 patients with only one copy of SMN2 also have atrial and/or ventricular septal defects, suggesting a more causal than chance relationship [130]. However, this correlation was not observed in type 1 SMA 
patients with more than one copy of SMN2 [130]. Additional clinical reports of individuals and siblings have also described an association between SMA type 1 disease severity and heart abnormalities [131-133]. It has thus been proposed that the combination of SMA and congenital heart defects may be exclusive to type 1 SMA [131]. Concordantly, recent analyses of various SMA mouse models have identified striking defects in cardiac function and development [134-136]. However, the relevance of these observations in our understanding of SMA pathogenesis is still not quite clear. In fact, an early evaluation of cardiorespiratory response of SMA patients to exercise did not establish a correlation between their aerobic capacity and muscle strength [137]. It is therefore possible that the depletion of SMN in heart muscle may not be contributory to the severe pathology afflicting SMA patients.

\section{SMN function \& SMA pathology at the neuromuscular junction}

In light of the motor neuron defects and muscle atrophy characterizing SMA, recent research has focused on the NMJ, the results of which are summarized in Table 2. Indeed, various groups have shown that SMN depletion results in abnormal endplate morphology, endplate denervation, neurofilament (NF) accumulation and perturbed function [112,138-140].

At the presynapse in the zebrafish model of SMA, a decrease in synaptic vesicle protein 2 (SV2), a protein responsible for normal neuronal transmission, has been reported [141]. Moreover, Kong and colleagues report a decrease in synaptic vesicle density in NMJs of SMA mice [139]. NF accumulation at the presynaptic terminal and preterminal axon has been described in multiple mouse models of SMA [112,138,139,142]. It thus appears that SMN depletion also affects the expression and localization of proteins important for normal functioning of the NMJ.

Several studies describe denervated NMJs in SMA models, characterized by reduced endplate occupancy and even complete endplate vacancy (Table 2) [140]. The denervation of the motor axon appears to be particularly associated with proximal muscles, which correlates with the proximal weakness observed in patients $[138,139]$. Interestingly, one group showed that motor neurons with a fast-synapsing phenotype display a greater denervation vulnerability than those with slow-synapsing characteristics [112]. As this aspect of the study was limited to the levator auris longus muscle the extent of the significance of this finding in unclear; however, this may suggest that developmental phenotype and/or motor neuron plasticity can have an impact on the vulnerability of a motor neuron to SMA-induced pathology [112].

It is well established that postsynaptic defects are also present in SMA. Immature motor endplates, assessed by their reduction in size and their decreased number of perforations, are prevalent in SMA [112,138,139,143]. Moreover, analyses of the acetylcholine receptor subunits, which

Table 2. Neuromuscular junction defects reported in various models of spinal muscular atrophy.

\begin{tabular}{|c|c|c|c|c|c|}
\hline Model & $\begin{array}{l}\text { Neurofilament } \\
\text { accumulation }\end{array}$ & $\begin{array}{l}\text { Abnormal } \\
\text { motor } \\
\text { endplates }\end{array}$ & Denervation & $\begin{array}{l}\text { NMJ } \\
\text { synaptic } \\
\text { function }\end{array}$ & Ref. \\
\hline $\begin{array}{l}\text { Mouse } \\
\text { Conditional neuronal KO }\end{array}$ & Yes & Yes & Yes & Not tested & [142] \\
\hline Drosophila & Not determined & Yes & Not determined & Abnormal & {$[127]$} \\
\hline 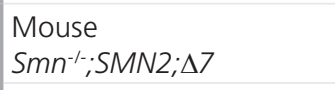 & Not determined & Yes & Yes (mild) & Not tested & [25] \\
\hline $\begin{array}{l}\text { Mouse } \\
\text { Smn } \\
\text { Smn } n^{-/-} ; S M N 2 \text { and } 2 ; \Delta 7\end{array}$ & Yes & Yes & Yes & Not tested & {$[112]$} \\
\hline $\begin{array}{l}\text { Mouse } \\
S m n^{-/-} ; S M N 2 ; \Delta 7\end{array}$ & Yes & Yes & Yes (mild) & Abnormal & {$[138]$} \\
\hline Drosophila & Not determined & Yes & Not determined & Not tested & [128] \\
\hline $\begin{array}{l}\text { Mouse } \\
\text { Smn }{ }^{-1 /} ; \operatorname{SMN} 2 ; \Delta 7\end{array}$ & Yes & Yes & $\begin{array}{l}\text { No (very limited } \\
\text { denervation) }\end{array}$ & Abnormal & [139] \\
\hline Zebrafish & Not determined & No & Not determined & Not tested & {$[141]$} \\
\hline $\begin{array}{l}\text { Mouse } \\
\text { Smn }{ }^{-1 / ;} \text {;SMN2 (N11/N46) }\end{array}$ & Yes & Yes & Yes (not quantified) & Abnormal & [114] \\
\hline
\end{tabular}


are bound to the postsynaptic motor end-plate, revealed a delay in the developmental switch from the embryonic subunit to the adult subunit $[138,139,144]$. Interestingly, in Drosophila, SMN localizes at the motor endplate but its function in this region has not yet been determined [128]. It is plausible that SMN has a specific role at the postsynapse and that its depletion contributes to the reported motor endplate defects, independent of presynaptic abnormalities [112]. A previous report suggests that SMN is present at the motor endplate in mice [70]. Future research should be aimed at confirming this finding as well as further investigating its function at the NMJ.

In light of the many morphological NMJ defects observed in SMA, it is not surprising that its function is also perturbed. Indeed, excitatory postsynaptic currents are reduced in Drosophila and mouse models of SMA, a finding likely attributable to a decrease in vesicle release $[127,139]$. Moreover, in response to a repetitive stimulation protocol, a greater number of SMA NMJs experienced intermittent transmission failures compared with controls [138]. It thus appears that loss of the SMN protein profoundly impacts proper NMJ function.

Different aspects of NMJ pathology appear to occur early in SMA mice. In the $\mathrm{Smn}^{-1}$;SMN2;SMND7 mouse model, Kariya et al. describe presynaptic abnormalities at postnatal day 0 , before any apparent disease symptoms [138]. In a study performed in $\mathrm{Smn}^{-1-} ; S M N 2$ mice, unoccupied endplates are detected as early as E18 [77]. However, the observed denervation is likely not attributable to aberrant lower motor neuron arborization, postsynaptic perturbations or gene-expression changes [145]. Interestingly, experiments that have increased the survival of SMA mouse models, via exercise or administration of compounds, also show an improvement in the maturation and morphology of the motor unit $[107,143,146]$. Further experiments are thus required to address the primary significance of NMJs in SMA pathophysiology and the function of SMN at the NMJs.

Identifying the mechanisms responsible for the NMJ defects in SMA should provide us with a better understanding of SMN's role in normal NMJ development. For the moment, the aberrant mechanism responsible for the accumulation of proteins in axons is unknown. It is unlikely that this pathology is specific to SMA, since it has been observed in other mouse models [147,148]. Rather, the accumulation of NFs may be indicative of the general breakdown of axonal transport. As discussed in a previous section, $\mathrm{SMN}$ also appears to play a role in the modulation of actin dynamics. Interestingly, abnormal regulation of actin dynamics can lead to the suppression of growth and sprouting at the NMJ [149]. The importance of axonal sprouting has been highlighted in a mouse model of mild SMA. Ciliary neurotrophic factor-induced sprouting in motor nerves appear to compensate for the motor neuron loss and endplate denervation observed in $\mathrm{Smn}^{+/-}$mice and preserve motor function [150].

Proper communication between skeletal muscle and motor neurons is essential for NMJ formation and maintenance [151]. Several intracellular pathways that are abnormally regulated in SMA models are implicated in NMJ assembly and function. Actin dynamics are essential in modulating different aspects of acetylcholine receptor organization via the Rho GTPases [151]. Myosin light chains are downstream targets of the Rho GTPase signaling pathway. Interestingly, recent findings show that SMN directly interacts with myosin regulatory light chain in skeletal muscle [48]. At the moment, it is unclear whether the increased activation of the RhoA/ROCK pathway observed in SMA models affects the motor neuron, the muscle or both via the NMJ. Treatment of SMA mice with a ROCK inhibitor, a synthetic compound that leads to actin rearrangements [152-155], resulted in a significant improvement in NMJ size and maturity [107]. Thus, deciphering if abnormal NMJ development is at the origin of SMA pathogenesis and what molecular mechanisms are responsible for these defects may be key in identifying novel targets and developing therapeutics to cure or alleviate the symptoms of SMA.

\section{Conclusion}

As highlighted throughout this article, although significant advancements have been made in understanding the pathogenesis of SMA, many questions remain unanswered. To study the many functions of the SMN protein, researchers have developed numerous cell and animal models of SMA. These models have lead to several proposed mechanisms thought to be responsible for the specific pathology of this neurodegenerative disease (FIgure 3). We have proposed that SMN plays a central role in regulating actin dynamics in motor neuron axons (FIgure 1). This idea is currently supported by several molecular changes reported in the expression and activity of actin-regulating proteins. We also review the contributions of muscle in the pathophysiology of SMA and show that for the moment 


\section{Review Boyer, Bowerman \& Kothary}

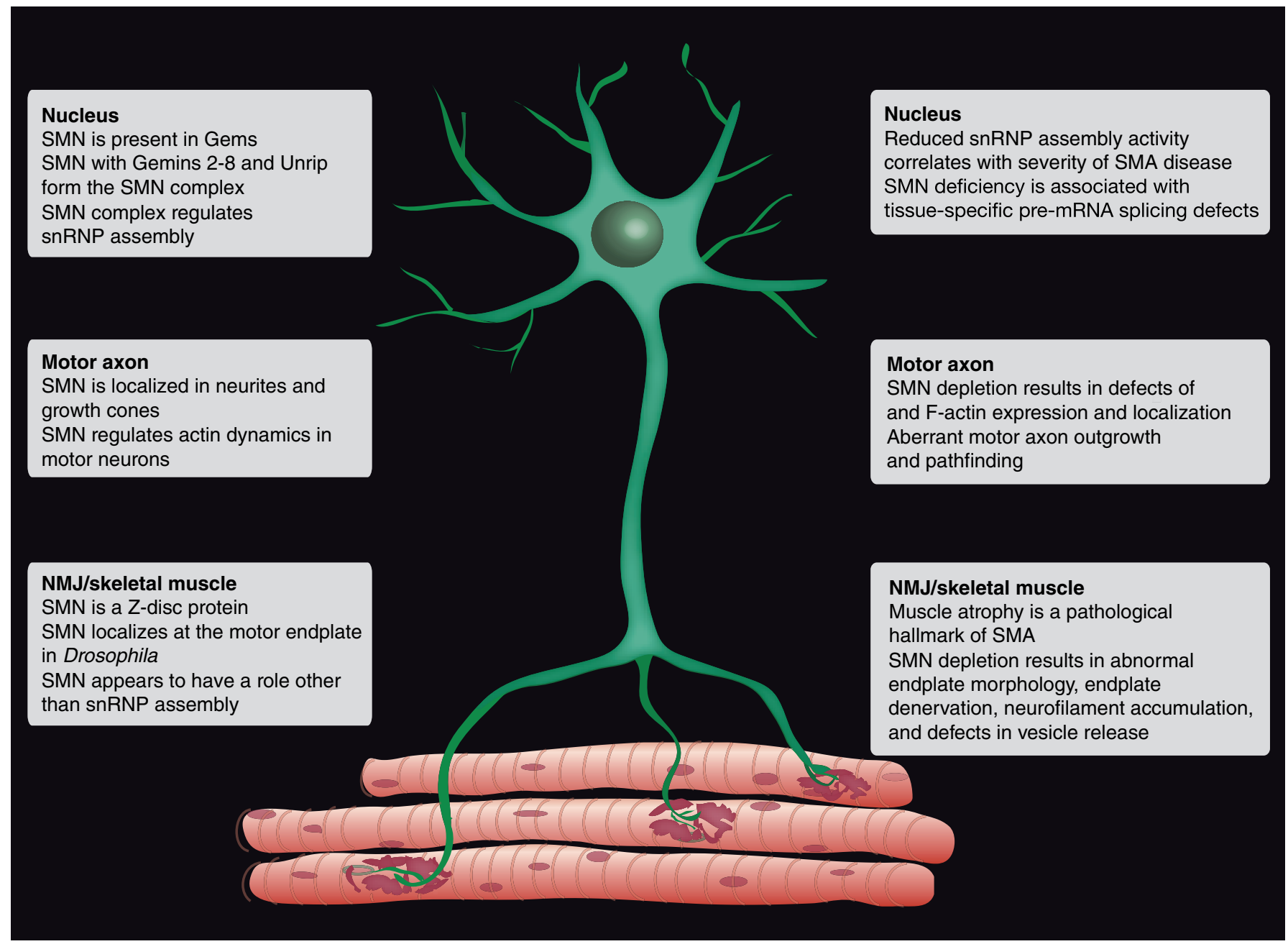

Figure 3. Survival motor neuron function and spinal muscular atrophy pathology. Diagram highlighting our understanding of SMN function and the consequences of SMN-depletion at the motor unit.

NMJ: Neuromuscular junction; SMA: Spinal muscular atrophy; SMN: Survival motor neuron; SnRNP: Small nuclear ribonucleoprotein.

its importance should not be overlooked. In addition, we discuss evidence that the neuronmuscle connections, the NMJs, display pre- and post-synaptic abnormalities in SMA models, suggesting that the defects may be at the root of SMA pathology. For the moment, the functions of SMN in muscle and at the NMJ are unclear.

At present, it is unknown why motor neurons are predominantly affected in SMA and how SMN depletion leads to SMA. The most well understood function of SMN is in snRNP biogenesis, which is important for pre-mRNA splicing. In motor neurons, $\mathrm{SMN}$ is localized in both the nucleus and axons. The role of SMN in the nucleus and in axons may be equally important in defining SMA pathogenesis. Further insight into the known functions of SMN and the discovery of novel roles for this protein will help to uncover the mechanism(s) behind this devastating disease.

\section{Future perspective}

Currently the SMA field is aggressively assessing the therapeutic value of several approaches, namely gene therapy and the administration of compounds that increase full-length SMN expression from the SMN2 gene [156]. However, additional basic research is required in order to better understand the function(s) of SMN and the molecular consequences of its depletion to allow researchers to develop specifically tailored therapeutics.

Multiple theories have been proposed attempting to explain how SMN depletion leads to SMA. However, some hypotheses are formulated based on end-stage analyses. Intuitively, the primary mechanism responsible for SMA should be dysregulated prior to the onset of any observable phenotype. We therefore suggest that future research aiming at identifying potential mechanisms responsible 
for SMA pathogenesis confirm their abnormalities and perturbations at a prephenotype stage of the disease.

In summary, future research should focus on identifying the specific pathways responsible for the particular motor neuron degeneration, muscular atrophy and NMJ defects that typify SMA. This will undoubtedly provide us with a better understanding of when and how to best treat SMA patients.

\section{Financial \& competing interests disclosure}

The authors have no relevant affliations or financial involvement with any organization or entity with a financial interest in or financial conflict with the subject matter or materials discussed in the manuscript. This includes employment, consultancies, honoraria, stock ownership or options, expert testimony, grants or patents received or pending, or royalties.

No writing assistance was utilized in the production of this manuscript.

\section{Executive summary}

\section{Spinal muscular atrophy}

- Spinal muscular atrophy (SMA) is a recessive autosomal neurodegenerative disease caused by deletions or mutations in the survival motor neuron (SMN)1 gene.

- SMA is characterized by a loss of $\alpha$-motor neurons in the spinal cord and muscular atrophy of the limbs and trunk, which eventually lead to paralysis and in severe cases, death.

Small nuclear ribonucleoprotein assembly \& splicing

- The SMN complex binds the Sm core proteins to the small nuclear RNA (snRNA) to form small nuclear ribonucleoproteins (snRNPs).

- snRNPs identify and remove introns, essential for the maturation of mRNA.

- Splicing defects have been reported in SMA models, however, these are likely to be secondary effects of the disease, since most changes are observed in late-stage SMA.

\section{Actin dynamics in motor neurons}

- SMN depletion results in expression and localization defects of $\beta$ - and F-actin.

- Regulators of actin dynamics (profilin Ila, plastin 3, RhoA and Cdc42) are abnormally expressed and/or misregulated in SMA cell and mouse models.

- Inactivation of Rho-kinase results in the increased survival of an intermediate SMA mouse model.

\section{Spinal muscular atrophy pathology in muscle}

- In striated muscle, SMN is localized at Z-discs.

- The contribution of muscle in the pathophysiology of SMA is currently not well defined.

- Cardiac defects are prevalent in patients with severe SMA.

Spinal muscular atrophy pathology in neuromuscular junctions

- SV2 and neurofilaments are abnormally expressed at presynaptic regions.

- SMA neuromuscular junctions (NMJs) display pre- and post-synaptic defects.

- It is not yet clear if the observed NMJ defects are a primary contributor to SMA pathogenesis.

\section{Conclusion}

- Aberrant splicing has yet to be linked to the motor neuron degeneration in SMA.

- Abnormal regulation of actin dynamics appears to be of primary importance in SMA.

- Further characterization of the functions of the SMN protein in neurons, muscle and at the NMJ is necessary to allow for the optimal development of therapeutic strategies.

\section{Bibliography}

Papers of special note have been highlighted as:

- of interest

-" of considerable interest

1. Crawford TO, Pardo CA: The neurobiology of childhood spinal muscular atrophy. Neurobiol. Dis. 3(2), 97-110 (1996).

2. Pearn J: Incidence, prevalence, and gene frequency studies of chronic childhood spinal muscular atrophy. J. Med. Genet. 15(6), 409-413 (1978).

3. Dubowitz V: Very severe spinal muscular atrophy (SMA type 0): an expanding clinical phenotype. Eur. J. Paediatr. Neurol. 3(2), 49-51 (1999).
4. MacLeod MJ, Taylor JE, Lunt PW, Mathew CG, Robb SA: Prenatal onset spinal muscular atrophy. Eur. J. Paediatr. Neurol. 3(2), 65-72 (1999).

5. Pearn J: Classification of spinal muscular atrophies. Lancet 1(8174), 919-922 (1980).

6. Munsat TL, Davies KE: International SMA Consortium Meeting. (26-28 June 1992, Bonn, Germany). Neuromuscul. Disord. 2(5-6), 423-428 (1992).

7. Lefebvre S, Burglen L, Reboullet $\mathrm{S}$ et al: Identification and characterization of a spinal muscular atrophy-determining gene. Cell 80(1), 155-165 (1995).
- Seminal paper that first identified and described the spinal muscular atrophy (SMA) disease-causing gene known as survival motor neuron $(S M N) 1$.

8. DiDonato CJ, Chen XN, Noya D, Korenberg JR, Nadeau JH, Simard LR: Cloning, characterization, and copy number of the murine survival motor neuron gene: homolog of the spinal muscular atrophy-determining gene. Genome Res. 7(4), 339-352 (1997).

9. Lorson CL, Hahnen E, Androphy EJ, Wirth B: A single nucleotide in the $S M N$ gene regulates splicing and is responsible for spinal muscular atrophy. Proc. Natl Acad. Sci. USA 96(11), 6307-6311 (1999). 
10. Cho S, Dreyfuss G: A degron created by SMN2 exon 7 skipping is a principal contributor to spinal muscular atrophy severity. Genes Dev. 24(5), 438-442 (2010).

11. Lefebvre S, Burlet P, Liu Q et al.: Correlation between severity and SMN protein level in spinal muscular atrophy. Nat. Genet. 16(3), 265-269 (1997).

12. Liu H, Shafey D, Moores JN, Kothary R: Neurodevelopmental consequences of Smn depletion in a mouse model of spinal muscular atrophy. J. Neurosci. Res. 88(1), 111-122 (2010).

13. Liu Q, Dreyfuss G: A novel nuclear structure containing the survival of motor neurons protein. EMBO J.15(14), 3555-3565 (1996).

14. Young PJ, Le TT, thi Man N, Burghes AH, Morris GE: The relationship between SMN, the spinal muscular atrophy protein, and nuclear coiled bodies in differentiated tissues and cultured cells. Exp. Cell Res. 256(2), 365-374 (2000).

15. Jablonka S, Bandilla M, Wiese S et al.: Co-regulation of survival of motor neuron (SMN) protein and its interactor SIP1 during development and in spinal muscular atrophy. Hum. Mol. Genet. 10(5), 497-505 (2001).

16. Fan L, Simard LR: Survival motor neuron $(\mathrm{SMN})$ protein: role in neurite outgrowth and neuromuscular maturation during neuronal differentiation and development. Hum. Mol. Genet. 11(14), 1605-1614 (2002).

17. Cifuentes-Diaz C, Frugier T, Tiziano FD et al.: Deletion of murine SMN exon 7 directed to skeletal muscle leads to severe muscular dystrophy. J. Cell Biol. 152(5), 1107-1114 (2001).

18. Shafey D, Cote PD, Kothary R: Hypomorphic Smn knockdown C2C12 myoblasts reveal intrinsic defects in myoblast fusion and myotube morphology. Exp. Cell Res. 311(1), 49-61 (2005).

19. Walker MP, Rajendra TK, Saieva L, Fuentes JL, Pellizzoni L, Matera AG: SMN complex localizes to the sarcomeric Z-disc and is a proteolytic target of calpain. Hum. Mol. Genet. 17(21), 3399-3410 (2008).

- Describes a previously unexplored sarcomeric localization of SMN in striated muscle. SMN is localized at Z-discs and is likely to have a unique function based on the absence of uridine-rich small nuclear ribonucleoproteins (snRNPs) in muscle.

20. Park GH, Kariya S, Monani UR: Spinal muscular atrophy: new and emerging insights from model mice. Curr. Neurol. Neurosci. Rep. 10 (2), 108-117 (2010).

21. Jablonka S, Schrank B, Kralewski M, Rossoll W, Sendtner M: Reduced survival motor neuron $(S M N)$ gene dose in mice leads to motor neuron degeneration: an animal model for spinal muscular atrophy type III. Hum. Mol. Genet. 9(3), 341-346 (2000).

22. Monani UR, Coovert DD, Burghes AH: Animal models of spinal muscular atrophy. Hum. Mol. Genet. 9(16), 2451-2457 (2000).

23. Hsieh-Li HM, Chang JG, Jong YJ et al.: A mouse model for spinal muscular atrophy. Nat. Genet. 24(1), 66-70 (2000).

24. Monani UR, Sendtner M, Coovert DD et al.: The human centromeric survival motor neuron gene (SMN2) rescues embryonic lethality in $\operatorname{Smn}\left({ }^{--}\right)$mice and results in a mouse with spinal muscular atrophy. Hum. Mol. Genet. 9(3), 333-339 (2000).

25. Le TT, Pham LT, Butchbach ME et al.: SMN 87 , the major product of the centromeric survival motor neuron (SMN2) gene, extends survival in mice with spinal muscular atrophy and associates with full-length SMN. Hum. Mol. Genet. 14(6), 845-857 (2005).

26. Bowerman M, Anderson CL, Beauvais A, Boyl PP, Witke W, Kothary R: SMN, profilin IIa and plastin 3: a link between the deregulation of actin dynamics and SMA pathogenesis. Mol. Cell Neurosci. 42(1), 66-74 (2009).

27. Matera AG, Frey MR: Coiled bodies and gems: Janus or gemini? Am. J. Hum. Genet. 63(2), 317-321 (1998).

28. Paushkin S, Gubitz AK, Massenet S, Dreyfuss G: The SMN complex, an assemblyosome of ribonucleoproteins. Curr. Opin. Cell Biol. 14(3), 305-312 (2002).

29. Battle DJ, Kasim M, Yong J et al.: The SMN complex: an assembly machine for RNPs. Cold Spring Harb. Symp. Quant. Biol. 71, 313-320 (2006).

30. Burghes AH, Beattie CE: Spinal muscular atrophy: why do low levels of survival motor neuron protein make motor neurons sick? Nat. Rev. Neurosci. 10(8), 597-609 (2009).

31. Will CL, Luhrmann R: Spliceosomal UsnRNP biogenesis, structure and function. Curr. Opin. Cell Biol. 13(3), 290-301 (2001).

32. Chari A, Golas MM, Klingenhager M et al:: An assembly chaperone collaborates with the SMN complex to generate spliceosomal SnRNPs. Cell 135(3), 497-509 (2008).

- Explains the assembly mechanism of snRNP biogenesis and highlights the role of the SMN complex in this process.

33. Friesen WJ, Wyce A, Paushkin S et al.: A novel WD repeat protein component of the methylosome binds Sm proteins. J. Biol. Chem. 277(10), 8243-8247 (2002).
34. Pu WT, Krapivinsky GB, Krapivinsky L, Clapham DE: pICln inhibits snRNP biogenesis by binding core spliceosomal proteins. Mol. Cell. Biol. 19(6), 4113-4120 (1999).

35. Meister G, Eggert C, Buhler D, Brahms H, Kambach C, Fischer U: Methylation of Sm proteins by a complex containing PRMT5 and the putative $\mathrm{U}$ snRNP assembly factor pICln. Curr. Biol. 11(24), 1990-1994 (2001).

36. Pesiridis GS, Diamond E, Van Duyne GD: Role of pICLn in methylation of Sm proteins by PRMT5. J. Biol. Chem. 284(32), 21347-21359 (2009).

37. Friesen WJ, Paushkin S, Wyce A et al: The methylosome, a $20 \mathrm{~S}$ complex containing JBP1 and $\mathrm{pICln}$, produces dimethylargininemodified Sm proteins. Mol. Cell. Biol. 21(24), 8289-8300 (2001).

38. Gonsalvez GB, Tian L, Ospina JK, Boisvert FM, Lamond AI, Matera AG: Two distinct arginine methyltransferases are required for biogenesis of $\mathrm{Sm}$-class ribonucleoproteins. J. Cell Biol. 178(5), 733-740 (2007).

39. Buhler D, Raker V, Luhrmann R, Fischer U: Essential role for the tudor domain of SMN in spliceosomal $U$ snRNP assembly: implications for spinal muscular atrophy. Hum. Mol. Genet. 8(13), 2351-2357 (1999).

40. Côté J, Richard S: Tudor domains bind symmetrical dimethylated arginines. J. Biol. Chem. 280(31), 28476-28483 (2005).

41. Liu Q, Fischer U, Wang F, Dreyfuss G: The spinal muscular atrophy disease gene product, SMN, and its associated protein SIP1 are in a complex with spliceosomal snRNP proteins. Cell 90(6), 1013-1021 (1997).

42. Meister G, Buhler D, Pillai R, Lottspeich F, Fischer $\mathrm{U}$ : A multiprotein complex mediates the ATP-dependent assembly of spliceosomal U snRNPs. Nat. Cell Biol. 3(11), 945-949 (2001).

43. Pellizzoni L, Yong J, Dreyfuss G: Essential role for the SMN complex in the specificity of snRNP assembly. Science 298(5599), 1775-1779 (2002).

44. Palfi Z, Jaé N, Preusser C et al.: SMN-assisted assembly of snRNP-specific $S m$ cores in trypanosomes. Genes Dev. 23(14), 1650-1664 (2009).

45. Eggert C, Chari A, Laggerbauer B, Fischer U: Spinal muscular atrophy: the RNP connection. Trends Mol. Med. 12(3), 113-121 (2006).

46. Matera AG, Shpargel KB: Pumping RNA: nuclear bodybuilding along the RNP pipeline. Curr. Opin. Cell Biol. 18(3), 317-324 (2006). 
47. Boisvert FM, Cote J, Boulanger MC et al: : Symmetrical dimethylarginine methylation is required for the localization of SMN in Cajal bodies and pre-mRNA splicing. J. Cell Biol. 159(6), 957-969 (2002).

48. Shafey D, Boyer JG, Bhanot K, Kothary R: Identification of novel interacting protein partners of SMN using tandem affinity purification. J. Proteome Res. 9(4), 1659-1669 (2010).

49. Trinkle-Mulcahy L, Boulon S, Lam YW et al.: Identifying specific protein interaction partners using quantitative mass spectrometry and bead proteomes. J. Cell Biol. 183(2), 223-239 (2008).

50. Mouaikel J, Verheggen C, Bertrand E, Tazi J, Bordonne R: Hypermethylation of the cap structure of both yeast snRNAs and snoRNAs requires a conserved methyltransferase that is localized to the nucleolus. Mol. Cell 9(4), 891-901 (2002).

51. Mouaikel J, Narayanan U, Verheggen C et al.: Interaction between the small-nuclear-RNA cap hypermethylase and the spinal muscular atrophy protein, survival of motor neuron. Mol. Cell 4(6), 616-622 (2003).

52. Palacios I, Hetzer M, Adam SA, Mattaj IW: Nuclear import of U snRNPs requires importin $\beta$. EMBO J. 16(22), 6783-6792 (1997).

53. Narayanan U, Ospina JK, Frey MR, Hebert MD, Matera AG: SMN, the spinal muscular atrophy protein, forms a pre-import snRNP complex with snurportin1 and importin- $\beta$. Hum. Mol. Genet. 11(15), 1785-1795 (2002).

54. Narayanan U, Achsel T, Luhrmann R, Matera AG: Coupled in vitro import of $\mathrm{U}$ snRNPs and SMN, the spinal muscular atrophy protein. Mol. Cell 16(2), 223-234 (2004).

55. Huber J, Cronshagen U, Kadokura M et al.: Snurportin1, an m3G-cap-specific nuclear import receptor with a novel domain structure. EMBO J. 17(14), 4114-4126 (1998).

56. Carvalho T, Almeida F, Calapez A, Lafarga M, Berciano MT, Carmo-Fonseca M: The spinal muscular atrophy disease gene product, SMN: a link between snRNP biogenesis and the Cajal (coiled) body. J. Cell Biol. 147(4), 715-728 (1999).

57. Hebert MD, Szymczyk PW, Shpargel KB, Matera AG: Coilin forms the bridge between Cajal bodies and SMN, the spinal muscular atrophy protein. Genes Dev. 15(20), 2720-2729 (2001).

58. Tucker KE, Berciano MT, Jacobs EY et al.: Residual Cajal bodies in coilin knockout mice fail to recruit $S m$ snRNPs and SMN, the spinal muscular atrophy gene product. J. Cell Biol. 154(2), 293-307 (2001).
59. Gonsalvez GB, Praveen K, Hicks AJ, Tian L, Matera AG: Sm protein methylation is dispensable for snRNP assembly in Drosophila melanogaster. RNA 14(5), 878-887 (2008).

60. Campion Y, Neel H, Gostan T, Soret J, Bordonne R: Specific splicing defects in $S$. pombe carrying a degron allele of the survival of motor neuron gene. $E M B O J$. (2010).

61. Winkler C, Eggert C, Gradl D et al.: Reduced U snRNP assembly causes motor axon degeneration in an animal model for spinal muscular atrophy. Genes Dev. 19(19), 2320-2330 (2005).

62. Gabanella F, Butchbach ME, Saieva L, Carissimi C, Burghes AH, Pellizzoni L: Ribonucleoprotein assembly defects correlate with spinal muscular atrophy severity and preferentially affect a subset of spliceosomal snRNPs. PLoS One 2(9), E921 (2007).

63. Pellizzoni L, Charroux B, Dreyfuss G: SMN mutants of spinal muscular atrophy patients are defective in binding to snRNP proteins. Proc. Natl Acad. Sci. USA 96(20), 1116711172 (1999).

64. Wan L, Battle DJ, Yong J et al.: The survival of motor neurons protein determines the capacity for snRNP assembly: biochemical deficiency in spinal muscular atrophy. Mol. Cell. Biol. 25(13), 5543-5551 (2005).

65. Carrel TL, McWhorter ML, Workman E et al:: Survival motor neuron function in motor axons is independent of functions required for small nuclear ribonucleoprotein biogenesis. J. Neurosci. 26(43), 11014-11022 (2006).

- Using the zebrafish as a model, the authors knockdown SMN and rescue the motor axon defects independently of snRNP assembly. These findings suggest that SMN has a motor axon-specific role.

66. Pellizzoni L, Kataoka N, Charroux B, Dreyfuss G: A novel function for SMN, the spinal muscular atrophy disease gene product, in pre-mRNA splicing. Cell 95(5), 615-624 (1998).

67. Zhang Z, Lotti F, Dittmar K et al:: SMN deficiency causes tissue-specific perturbations in the repertoire of snRNAs and widespread defects in splicing. Cell 133(4), 585-600 (2008).

68. Fox-Walsh KL, Hertel KJ: Splice-site pairing is an intrinsically high fidelity process. Proc. Natl Acad. Sci. USA 106(6), 1766-1771 (2009).

69. Baümer D, Lee S, Nicholson G et al.: Alternative splicing events are a late feature of pathology in a mouse model of spinal muscular atrophy. PLoS Genet. 5(12), E1000773 (2009).
70. Fan L, Simard LR: Survival motor neuron $(\mathrm{SMN})$ protein: role in neurite outgrowth and neuromuscular maturation during neuronal differentiation and development. Hum. Mol. Genet. 11(14), 1605-1614 (2002).

71. McWhorter ML, Monani UR, Burghes AH, Beattie CE: Knockdown of the survival motor neuron $(\mathrm{Smn})$ protein in zebrafish causes defects in motor axon outgrowth and pathfinding. J. Cell Biol. 162(5), 919-931 (2003).

72. Shafey D, MacKenzie AE, Kothary R: Neurodevelopmental abnormalities in neurosphere-derived neural stem cells from SMN-depleted mice. J. Neurosci. Res. 86(13), 2839-2847 (2008).

73. Bowerman M, Shafey D, Kothary R: Smn depletion alters profilin II expression and leads to upregulation of the RhoA/ROCK pathway and defects in neuronal integrity. J. Mol. Neurosci. 32(2), 120-131 (2007).

74. van Bergeijk J, Rydel-Konecke K, Grothe C, Claus P: The spinal muscular atrophy gene product regulates neurite outgrowth: importance of the C terminus. Faseb J. 21(7), 1492-1502 (2007).

75. Zhang HL, Pan F, Hong D, Shenoy SM, Singer RH, Bassell GJ: Active transport of the survival motor neuron protein and the role of exon-7 in cytoplasmic localization. J. Neurosci. 23(16), 6627-6637 (2003).

76. Rossoll W, Jablonka S, Andreassi C et al.: Smn, the spinal muscular atrophydetermining gene product, modulates axon growth and localization of $\beta$-actin mRNA in growth cones of motoneurons. J. Cell Biol. 163(4), 801-812 (2003).

- Along with [92], the authors demonstrate that SMN associates with heterogeneous nuclear ribonucleoprotein $R$ (hnRNP-R) in motor axons and that the deletion of SMN1 impacts the localization of $\beta$-actin in primary motor neuron cultures. SMN forms a complex with hnRNP-R and $\beta$-actin to transport the $\beta$-actin to the growth cone of motor axons.

77. McGovern VL, Gavrilina TO, Beattie CE, Burghes AH: Embryonic motor axon development in the severe SMA mouse. Hum. Mol. Genet. 17(18), 2900-2909 (2008).

78. Murray LM, Lee S, Baumer D, Parson SH, Talbot K, Gillingwater TH: Pre-symptomatic development of lower motor neuron connectivity in a mouse model of severe spinal muscular atrophy. Hum. Mol. Genet. 19(3), 420-433

79. Cingolani LA, Goda Y: Actin in action: the interplay between the actin cytoskeleton and synaptic efficacy. Nat. Rev. Neurosci. 9(5), 344-356 (2008). 
80. da Silva JS, Dotti CG: Breaking the neuronal sphere: regulation of the actin cytoskeleton in neuritogenesis. Nat. Rev. Neurosci. 3(9), 694-704 (2002).

81. Bray D, Chapman K: Analysis of microspike movements on the neuronal growth cone. J. Neurosci. 5(12), 3204-3213 (1985).

82. Landis DM, Hall AK, Weinstein LA, Reese TS: The organization of cytoplasm at the presynaptic active zone of a central nervous system synapse. Neuron 1(3), 201-209 (1988).

83. Fifkova E, Delay RJ: Cytoplasmic actin in neuronal processes as a possible mediator of synaptic plasticity. J. Cell Biol. 95(1), 345-350 (1982).

84. Dillon C, Goda Y: The actin cytoskeleton: integrating form and function at the synapse. Annu. Rev. Neurosci. 28, 25-55 (2005).

85. Sakaba T, Neher E: Involvement of actin polymerization in vesicle recruitment at the calyx of Held synapse. J. Neurosci. 23(3), 837-846 (2003).

86. Shupliakov O, Bloom O, Gustafsson JS et al.: Impaired recycling of synaptic vesicles after acute perturbation of the presynaptic actin cytoskeleton. Proc. Natl Acad. Sci. USA 99(22), 14476-14481 (2002).

87. Zhang $\mathrm{H}$, Xing L, Rossoll W, Wichterle $\mathrm{H}$, Singer RH, Bassell GJ: Multiprotein complexes of the survival of motor neuron protein SMN with Gemins traffic to neuronal processes and growth cones of motor neurons. J. Neurosci. 26(33), 8622-8632 (2006).

88. Todd AG, Shaw DJ, Morse R, Stebbings H, Young PJ: SMN and the Gemin proteins form sub-complexes that localise to both stationary and dynamic neurite granules. Biochem. Biophys. Res. Commun. 394(1), 211-216 (2010).

89. Todd AG, Morse R, Shaw DJ, McGinley S, Stebbings H, Young PJ: SMN, Gemin2 and Gemin3 associate with $\beta$-Actin mRNA in the cytoplasm of neuronal cells in vitro. J. Mol. Biol. 401(5), 681-689 (2010).

90. Mourelatos Z, Abel L, Yong J, Kataoka N, Dreyfuss G: SMN interacts with a novel family of hnRNP and spliceosomal proteins. EMBO J. 20(19), 5443-5452 (2001).

91. Glinka M, Herrmann T, Funk $N$ et al.: The heterogeneous nuclear ribonucleoprotein- $\mathrm{R}$ is necessary for axonal $\beta$-actin mRNA translocation in spinal motor neurons. Hum. Mol. Genet. 19(10), 1951-1966 (2010).

92. Rossoll W, Kroning AK, Ohndorf UM, Steegborn C, Jablonka S, Sendtner M: Specific interaction of $S \mathrm{mn}$, the spinal muscular atrophy determining gene product, with hnRNP-R and gry-rbp/hnRNP-Q: a role for $\mathrm{Smn}$ in RNA processing in motor axons? Hum. Mol. Genet. 11(1), 93-105 (2002).
- Along with [76], the authors demonstrate that SMN associates with hnRNP-R in motor axons and that the deletion of SMN1 impacts the localization of $\beta$-actin in primary motor neuron cultures. SMN forms a complex with hnRNP-R and $\beta$-actin to transport the $\beta$-actin to the growth cone of motor axons.

93. Tadesse H, Deschenes-Furry J, Boisvenue S, Cote J: $\mathrm{KH}$-type splicing regulatory protein interacts with survival motor neuron protein and is misregulated in spinal muscular atrophy. Hum. Mol. Genet. 17(4), 506-524 (2008).

94. Bowerman M, Shafey D, Kothary R: Smn depletion alters profilin II expression and leads to upregulation of the RhoA/ ROCK pathway and defects in neuronal integrity. J. Mol. Neurosci. 32(2), 120-131 (2007).

- Using SMN-depleted PC12 cells, the authors identify the actin regulators profilin IIa and RhoA as being abnormally expressed and activated, respectively. These findings have led to further characterization of these pathways in SMA mice and how they can be used as therapeutic targets.

95. Schnell E, Nicoll RA: Hippocampal synaptic transmission and plasticity are preserved in myosin Va mutant mice. J. Neurophysiol. 85(4), 1498-1501 (2001).

96. Ning K, Drepper C, Valori CF et al.: PTEN depletion rescues axonal growth defect and improves survival in SMN-deficient motor neurons. Hum. Mol. Genet. 19(16), 3159-3168 (2010).

97. Di Nardo A, Gareus R, Kwiatkowski D, Witke W: Alternative splicing of the mouse profilin II gene generates functionally different profilin isoforms. J. Cell. Sci. 113(Pt 21), 3795-3803 (2000).

98. Lambrechts A, Braun A, Jonckheere V et al: Profilin II is alternatively spliced, resulting in profilin isoforms that are differentially expressed and have distinct biochemical properties. Mol. Cell. Biol. 20(21), 82098219 (2000).

99. Giesemann T, Rathke-Hartlieb S, Rothkegel $M$ et al:: A role for polyproline motifs in the spinal muscular atrophy protein SMN. Profilins bind to and colocalize with $\mathrm{Smn}$ in nuclear gems. J. Biol. Chem. 274(53), 37908-37914 (1999).

100. Sharma A, Lambrechts A, Hao le T et al:: A role for complexes of survival of motor neurons (SMN) protein with gemins and profilin in neurite-like cytoplasmic extensions of cultured nerve cells. Exp. Cell Res. 309(1), 185-197 (2005).
101. Da Silva JS, Medina M, Zuliani C, Di Nardo A, Witke W, Dotti CG: RhoA/ROCK regulation of neuritogenesis via profilin IIamediated control of actin stability. J. Cell Biol. 162(7), 1267-1279 (2003).

102. Oprea GE, Krober S, McWhorter ML et al.: Plastin 3 is a protective modifier of autosomal recessive spinal muscular atrophy. Science 320 (5875), 524-527 (2008).

103. Giganti A, Plastino J, Janji B et al.: Actinfilament cross-linking protein T-plastin increases Arp2/3-mediated actin-based movement. J. Cell. Sci. 118(Pt 6), 1255-1265 (2005).

104. Glenney JR Jr, Kaulfus P, Matsudaira P, Weber K: F-actin binding and bundling properties of fimbrin, a major cytoskeletal protein of microvillus core filaments. J. Biol. Chem. 256(17), 9283-9288 (1981).

105. Luo L, Jan LY, Jan YN: Rho family GTP-binding proteins in growth cone signalling. Curr. Opin. Neurobiol. 7(1), 81-86 (1997).

106. Negishi M, Katoh H: Rho family GTPases as key regulators for neuronal network formation. J. Biochem. 132(2), 157-166 (2002).

107. Bowerman M, Beauvais A, Anderson CL, Kothary R: Rho-kinase inactivation prolongs survival of an intermediate SMA mouse model. Hum. Mol. Genet. 19(8), 1468-1478 (2010).

- The authors administer the Y-27632 compound, a Rho-kinase inhibitor, to the $S m n^{2 B /-}$ SMA mouse model. This treatment protocol resulted in a significant increase in lifespan, independent of SMN expression. This study identifies the actin cytoskeleton pathways as possible therapeutic targets for SMA.

108. Amano M, Ito M, Kimura K et al:: Phosphorylation and activation of myosin by Rho-associated kinase (Rho-kinase). J. Biol. Chem. 271(34), 20246-20249 (1996).

109. Uehata M, Ishizaki T, Satoh H et al.: Calcium sensitization of smooth muscle mediated by a Rho-associated protein kinase in hypertension. Nature 389 (6654), 990-994 (1997).

110. Gabanella F, Carissimi C, Usiello A, Pellizzoni L: The activity of the spinal muscular atrophy protein is regulated during development and cellular differentiation. Hum. Mol. Genet. 14(23), 3629-3642 (2005).

111. Giavazzi A, Setola V, Simonati A, Battaglia G: Neuronal-specific roles of the survival motor neuron protein: evidence from survival motor neuron expression patterns in the developing human central nervous system. J. Neuropathol. Exp. Neurol. 65(3), 267-277 (2006). 
112. Murray LM, Comley LH, Thomson D, Parkinson N, Talbot K, Gillingwater TH: Selective vulnerability of motor neurons and dissociation of pre- and post-synaptic pathology at the neuromuscular junction in mouse models of spinal muscular atrophy. Hum. Mol. Genet. 17(7), 949-962 (2008).

\section{- Detailed analysis describing} neuromuscular junction defects in mouse models of severe SMA.

113. Jablonka S, Rossoll W, Schrank B, Sendtner M: The role of SMN in spinal muscular atrophy. J. Neurol. 247(Suppl. 1), I37-I42 (2000).

114. Michaud M, Arnoux T, Bielli S et al.: Neuromuscular defects and breathing disorders in a new mouse model of spinal muscular atrophy. Neurobiol. Dis. 38(1), $125-135$ (2010).

115. Braun S, Croizat B, Lagrange MC, Warter JM, Poindron P: Constitutive muscular abnormalities in culture in spinal muscular atrophy. Lancet 345(8951), 694-695 (1995).

116. Martinez-Hernandez R, Soler-Botija C, Also E et al.: The developmental pattern of myotubes in spinal muscular atrophy indicates prenatal delay of muscle maturation. J. Neuropathol. Exp. Neurol. 68(5), 474-481 (2009).

117. Nicole S, Desforges B, Millet G et al.: Intact satellite cells lead to remarkable protection against $S m n$ gene defect in differentiated skeletal muscle. J. Cell Biol. 161(3), 571-582 (2003).

118. Vitte JM, Davoult B, Roblot N et al.: Deletion of murine Smn exon 7 directed to liver leads to severe defect of liver development associated with iron overload. Am. J. Pathol. 165(5), 1731-1741 (2004).

119. Rajendra TK, Gonsalvez GB, Walker MP, Shpargel KB, Salz HK, Matera AG: A Drosophila melanogaster model of spinal muscular atrophy reveals a function for SMN in striated muscle. J. Cell Biol. 176(6), 831-841 (2007).

120. Haddad F, Roy RR, Zhong H, Edgerton VR, Baldwin KM: Atrophy responses to muscle inactivity. II. Molecular markers of protein deficits. J. Appl. Physiol. 95(2), 791-802 (2003).

121. Bartoli M, Richard I: Calpains in muscle wasting. Int. J. Biochem. Cell Biol. 37(10), 2115-2133 (2005).

122. Dobrowolny G, Giacinti C, Pelosi L et al.: Muscle expression of a local Igf-1 isoform protects motor neurons in an ALS mouse model. J. Cell Biol. 168(2), 193-199 (2005).
123. Kaspar BK, Llado J, Sherkat N, Rothstein JD, Gage FH: Retrograde viral delivery of IGF-1 prolongs survival in a mouse ALS model. Science 301(5634), 839-842 (2003).

124. Palazzolo I, Stack C, Kong L et al.: Overexpression of IGF-1 in muscle attenuates disease in a mouse model of spinal and bulbar muscular atrophy. Neuron 63(3), 316-328 (2009).

125. Rose FF Jr, Mattis VB, Rindt H, Lorson CL: Delivery of recombinant follistatin lessens disease severity in a mouse model of spinal muscular atrophy. Hum. Mol. Genet. 18(6), 997-1005 (2009).

126. Sumner CJ, Wee CD, Warsing LC et al.: Inhibition of myostatin does not ameliorate disease features of severe spinal muscular atrophy mice. Hum. Mol. Genet. 18(17), 3145-3152 (2009).

127. Chan YB, Miguel-Aliaga I, Franks C et al.: Neuromuscular defects in a Drosophila survival motor neuron gene mutant. Hum. Mol. Genet. 12(12), 1367-1376 (2003).

128. Chang HC, Dimlich DN, Yokokura T et al:: Modeling spinal muscular atrophy in Drosophila. PLoS One 3(9), E3209 (2008).

129. Gavrilina TO, McGovern VL, Workman E et al: Neuronal SMN expression corrects spinal muscular atrophy in severe SMA mice while muscle-specific SMN expression has no phenotypic effect. Hum. Mol. Genet. 17(8), 1063-1075 (2008).

130. Rudnik-Schoneborn S, Heller R, Berg C et al: : Congenital heart disease is a feature of severe infantile spinal muscular atrophy. J. Med. Genet. 45(10), 635-638 (2008).

131. Menke LA, Poll-The BT, Clur SA et al.: Congenital heart defects in spinal muscular atrophy type I: a clinical report of two siblings and a review of the literature. Am. J. Med. Genet. A 146A(6), 740-744 (2008).

132. Burglen L, Spiegel R, Ignatius J et al:: SMN gene deletion in variant of infantile spinal muscular atrophy. Lancet 346(8970), 316-317 (1995).

133. Moller P, Moe N, Saugstad OD et al: : Spinal muscular atrophy type I combined with atrial septal defect in three sibs. Clin. Genet. 38(2), 81-83 (1990).

134. Bevan AK, Hutchinson KR, Foust KD et al:: Early heart failure in the SMN $\Delta 7$ model of spinal muscular atrophy and correction by postnatal scAAV9-SMN delivery. Hum. Mol. Genet. 19(20), 3895-3905 (2010).

135. Shababi M, Habibi J, Yang HT, Vale SM, Sewell WA, Lorson CL: Cardiac defects contribute to the pathology of spinal muscular atrophy models. Hum. Mol. Genet. 19(20), 4059-4071 (2010).
136. Heier CR, Satta R, Lutz C, Didonato CJ: Arrhythmia and cardiac defects are a feature of spinal muscular atrophy model mice. Hum. Mol. Genet. 19(20), 3906-3918 (2010).

137. Silva AC, Russo AK, Picarro IC et al.: Cardiorespiratory responses to exercise in patients with spinal muscular atrophy and limb-girdle dystrophy. Braz. J. Med. Biol. Res. 20(5), 565-568 (1987).

138. Kariya S, Park GH, Maeno-Hikichi Y et al:: Reduced SMN protein impairs maturation of the neuromuscular junctions in mouse models of spinal muscular atrophy. Hum. Mol. Genet. 17(16), 2552-2569 (2008).

139. Kong L, Wang X, Choe DW et al:: Impaired synaptic vesicle release and immaturity of neuromuscular junctions in spinal muscular atrophy mice. J. Neurosci. 29(3), 842-851 (2009).

- The authors examine the function of neuromuscular junctions and report abnormal synaptic vesicle density and release in SMA mice.

140. Murray LM, Talbot K, Gillingwater TH: Review: neuromuscular synaptic vulnerability in motor neurone disease: amyotrophic lateral sclerosis and spinal muscular atrophy. Neuropathol. Appl. Neurobiol. 36(2), 133-156 (2010).

141. Boon KL, Xiao S, McWhorter ML et al:: Zebrafish survival motor neuron mutants exhibit presynaptic neuromuscular junction defects. Hum. Mol. Genet. 18(19), 3615-3625 (2009).

142. Cifuentes-Diaz C, Nicole S, Velasco ME et al: Neurofilament accumulation at the motor endplate and lack of axonal sprouting in a spinal muscular atrophy mouse model. Hum. Mol. Genet. 11(12), 1439-1447. (2002).

143. Biondi O, Grondard C, Lecolle S et al.: Exercise-induced activation of NMDA receptor promotes motor unit development and survival in a type 2 spinal muscular atrophy model mouse. J. Neurosci. 28(4), 953-962 (2008).

144. Arnold AS, Gueye M, Guettier-Sigrist S et al.: Reduced expression of nicotinic AChRs in myotubes from spinal muscular atrophy I patients. Lab Invest. 84(10), 1271-1278 (2004).

145. Murray LM, Lee S, Baumer D, Parson SH, Talbot K, Gillingwater TH: Pre-symptomatic development of lower motor neuron connectivity in a mouse model of severe spinal muscular atrophy. Hum. Mol. Genet. 19(3), 420-433 (2010).

146. Avila AM, Burnett BG, Taye AA et al.: Trichostatin A increases SMN expression and survival in a mouse model of spinal muscular atrophy. J. Clin. Invest. 117(3), 659-671 (2007). 
147. Zhou J, Wang H, Feng Y, Chen J: Increased expression of cdk5/p25 in N2a cells leads to hyperphosphorylation and impaired axonal transport of neurofilament proteins. Life Sci. 86(13-14), 532-537 (2010).

148. Eyer J, Cleveland DW, Wong PC, Peterson AC: Pathogenesis of two axonopathies does not require axonal neurofilaments. Nature 391(6667), 584-587 (1998).

149. Ang LH, Chen W, Yao Y et al.: Lim kinase regulates the development of olfactory and neuromuscular synapses. Dev. Biol. 293(1), 178-190 (2006).

150. Simon CM, Jablonka S, Ruiz R, Tabares L, Sendtner M: Ciliary neurotrophic factorinduced sprouting preserves motor function in a mouse model of mild spinal muscular atrophy. Hum. Mol. Genet. 19(6), 973-986 (2010).

151. Wu H, Xiong WC, Mei L: To build a synapse: signaling pathways in neuromuscular junction assembly. Development 137(7), 1017-1033 (2010).

152. Wang L, Xue L, Yan H, Li J, Lu Y: Effects of ROCK inhibitor, Y-27632, on adhesion and mobility in esophageal squamous cell cancer cells. Mol. Biol. Rep. 37(4), 1971-1977 (2010).

153. Schaefer AW, Schoonderwoert VT, Ji L, Mederios N, Danuser G, Forscher P: Coordination of actin filament and microtubule dynamics during neurite outgrowth. Dev. Cell. 15(1), 146-162 (2008).
154. Rosner H, Moller W, Wassermann T, Mihatsch J, Blum M: Attenuation of actinomyosinII contractile activity in growth cones accelerates filopodiaguided and microtubule-based neurite elongation. Brain Res. 1176, 1-10 (2007).

155. Piccoli G, Rutishauser U, Bruses JL: $\mathrm{N}$-cadherin juxtamembrane domain modulates voltage-gated $\mathrm{Ca}^{2+}$ current via RhoA GTPase and Rho-associated kinase. J. Neurosci. 24(48), 10918-10923 (2004).

156. Lorson CL, Rindt H, Shababi M: Spinal muscular atrophy: mechanisms and therapeutic strategies. Hum. Mol. Genet. 19(R1), R111-R118 (2010). 